\title{
Spinal Leptomeningeal Lesion
}

National Cancer Institute

\section{Source}

National Cancer Institute. Spinal Leptomeningeal Lesion. NCI Thesaurus. Code C84359.

A non-neoplastic or neoplastic pathologic process affecting the leptomeninges of the spinal cord. 